\title{
Do Caos ao Mito: A Ascensão de um Presidente pela Óptica Psicanalítica
}

\author{
Mauricio Cardoso da Silva Junior ${ }^{1}$ \\ ${ }^{1}$ Universidade Estadual de Maringá, PR, Brasil.
}

\author{
Gustavo Adolfo Ramos Mello Neto ${ }^{1}$ \\ ${ }^{1}$ Universidade Estadual de Maringá, PR, Brasil.
}

Resumo: Este estudo tem como objetivo compreender, a partir da psicanálise, as moções afetivas tramadas no interior de nosso corpo social que tornaram possível a adesão massiva ao discurso conservador no pleito presidencial de 2018. Apoiando-nos em estudos sobre a psicologia de massas, em autores do pensamento social brasileiro e em pesquisas sobre os recentes acontecimentos do país, concluímos que a instabilidade política, econômica e moral ocorrida sobretudo a partir de 2013 e 2014, provocou um significativo solapamento das representações que garantiam uma mínima estabilidade à coletividade. Rondado pelo desamparo, mecanismos defensivos mais regressivos passaram a ser adotados no interior deste corpo social, dividindo-o internamente em dois extremos antagônicos, processo que lhe conferiu uma configuração polarizada. Esse cenário de cisão interna propiciou a emergência de discursos paranoides que seduziram grande parcela da população ao oferecer respostas assentadas em elementos persecutórios que circulavam no interior da massa, sustentando um discurso assentado no ódio direcionado ao polo inimigo.

Palavras-chave: Psicanálise, Cultura, Brasil, Política, Polarização.

\section{From Chaos to Myth: The Rise of a President under a Pshycoanalytic Optic}

\begin{abstract}
This study aims to understand, from a psychoanalytic point of view, the affective motions established in our social body that made possible a massive adherence to conservative speech in the 2018 presidential elections. Based on group psychology studies, on Brazilian social though authors, and research on recent events in the country, we concluded that political, moral, and economic instability ocurred mainly from the years 2013 and 2014 significantly undermined the representations that guaranteed minimal stability to the community. Facing helplessness, more regressive defense mechanisms acted within our social body, splitting it into two antagonistic extremes, that polarized it. This context of internal rupture was propitious for the emergence of paranoid discourses that seduced a large portion of the population by offering answers based on persecutory elements already considered among the masses, sustaining a hate speech directed at the enemy side.
\end{abstract}

Keywords: Psychoanalysis, Culture, Brazil, Politics, Polarization.

\section{Del Caos al Mito: El Ascenso de un Presidente desde el Punto de Vista Psicoanalítico}

Resumen: Este estudio tiene como objetivo comprender, desde un punto de vista psicoanalítico, las mociones afectivas tramadas en el interior de nuestro cuerpo social que hicieron posible la adhesión masiva al discurso conservador en las elecciones presidenciales de 2018 en Brasil. 
Con base en estudios sobre la psicología de grupos, en autores del pensamiento social brasileño y en investigaciones sobre los recientes acontecimientos del país, se concluye que la inestabilidad política, económica y moral que había ocurrido, sobre todo, a partir de los años 2013 y 2014, provocó un importante solapamiento de las representaciones que le garantizaban a la comunidad una mínima estabilidad. Con el desamparo, los mecanismos defensivos más regresivos pasaron a ser adoptados en el interior de este cuerpo social, dividiéndolo internamente en dos extremos antagónicos, proceso que le confirió una configuración polarizada. Este contexto de cisión interna propició el surgimiento de discursos paranoides que sedujeron gran parte de la población brasileña al ofrecerle respuestas basadas en elementos persecutorios que circulaban en su interior, sosteniendo un discurso de odio dirigido hacia el polo enemigo.

Palabras clave: Psicoanálisis, Cultura, Brasil, Política, Polarización.

Dividida: talvez essa seja uma percepção comum sobre como a sociedade brasileira se encontra atualmente. Uma cisão que, motivada por divergentes opiniões sobre os recentes acontecimentos no mundo da política, invadiu nosso cotidiano e perpassa nossos vínculos mais próximos, ocasionando amizades apartadas, famílias que se evitam em confraternizações, grupos de conversas em aplicativos desfeitos, brigas em redes sociais, hostilidades diversas, agressões físicas, chegando ao extremo da morte ${ }^{1}$. De repente, nos vimos entrincheirados entre esquerda e direita, progressistas e conservadores, socialistas e liberais, movimentos minoritários e "cidadãos de bem", "vermelhos" e "verde-amarelos", "petralhas" e "coxinhas". Grupos que nos convocam ao pertencimento e à identificação com suas respectivas pautas, pouco dialógicos e autoexcludentes, cada qual cerrado em suas respectivas certezas.

Nesse cenário de conflito, acompanhamos uma fulminante ascensão de Jair Messias Bolsonaro, uma liderança que seduziu grande parcela da população e alcançou o cargo máximo do país no pleito de 2018, imanizando, em torno de sua figura, uma série de anseios como respostas à situação de conflito e polarização.

É na tentativa de compreender este momento de nossa história circunscrito entre a situação de conflito (cisão) social e a adesão popular a um líder de ideário conservador, que nos debruçamos neste estudo de psicanálise extramuros ${ }^{2}$. Nos interessa, aqui, discutir não a materialidade dos fenômenos, o que provavelmente nos levaria a uma das extremidades da trincheira, mas seu nível fantasmático. Eis o trabalho da psicanálise, desde Freud, que buscamos desenvolver e apresentar ao leitor nas páginas que seguem.

\section{Pátria-mãe: a trama de afetos na formação do corpo social}

As nações, para Guibernau (1997), existem desde a Antiguidade e podem ser definidas enquanto comunidades organizadas em torno de uma língua, uma cultura, um passado e um projeto comuns, aspectos que favorecem o senso de pertença grupal, estabelecendo laços de solidariedade, e que dão corpo a uma identidade nacional, demarcando a diferenciação em relação ao estrangeiro.

Psicanaliticamente, compreende-se que se essas representações fornecedoras de coesão grupal são conscientes (uma língua, uma narrativa sobre sua história, projetos em comum), também possuem, para além de seus aspectos racionais, uma dimensão inconsciente, como qualquer criação humana. Funcionam como elaborações secundárias, ou seja, derivações ou arranjos que dão destinos a elementos mais seminais, primários, inconscientes. Assim, os grupos podem ser analisados (no sentido literal da palavra análise: desligar, separar suas partes) a partir do que há de mais elementar em sua formação: para Freud (1921/1996), consiste no elemento libidinal, sexual; para Mello Neto (1997), constitui o "átomo" da formação social.

Os grupos se constituem, para Freud (1921/1996), em torno de representações, desejos partilhados que

\footnotetext{
${ }^{1}$ Mestre Moa do Katende, morto com 12 facadas nas costas após uma discussão política com um apoiador do candidato Jair Bolsonaro, em 08 de outubro de 2018.

${ }^{2}$ Segundo Laplanche (1992), o termo psicanálise extramuros é preferível a "psicanálise aplicada", pois esta conota uma subjugação da análise extraclínica à clínica, como se não fosse um campo gerador de conhecimento e que requeresse uma metodologia própria.
} 
mobilizam laços libidinais. Os sujeitos, partilhando ideais, abstrações, tendências em comum, se identificam uns com os outros, tornando o outro, antes estranho, em semelhante - segundo Ramos (1997), um "outro-igual". A partir desse amor narcísico (investir no outro se o eu se reconhece nele), constitui-se um narcisismo interno do grupo, que sustenta sua unidade, sua identidade e sua diferenciação diante de outras massas. Por outro lado, a hostilidade não se volta para o "outro-igual", membro da massa, mas se desloca para o "outro-diferente", para outra coletividade (Freud, 1921/1996).

Essas representações compartilhadas, que atribuem um sentido à existência grupal, podem ser entendidas, a partir de Laplanche (2015), como recursos do inconsciente mito-simbólico. Os códigos e mitos presentes na cultura atuam, para o autor, como auxiliares de tradução para os sujeitos, fornecendo elementos que auxiliam os sujeitos na atribuição de ordem, sentido e razão à vida, o que os torna, portanto, elementos defensivos.

No interior dos grupos se destacam figuras que, por possuírem algumas características especiais sobretudo por sustentarem firmemente um ideal, fascinando e sendo admirado e prestigiado pelas multidões -, atuam de modo decisivo para a coesão grupal. Segundo Freud (1921/1996), tais sujeitos são os líderes, que despertam a atração da massa e exercem uma espécie de coerção que canaliza a libido de seus membros da satisfação individual para os fins da coletividade. O líder, na medida em que é um elemento isolado do restante da multidão e porta qualidades que os demais admiram e gostariam de ter para si, é colocado na posição de ideal do eu (o que os demais aspiram a ser, um exemplo a ser seguido e alcançado).

Assim as ligações libidinais tramadas no interior do grupo se estabelecem, segundo Ramos (1997), a partir de dois eixos que formam uma ligação em cruz: um horizontal, intersubjetivo, concernente às relações entre as pessoas e o laço que as une, e um vertical, institucional, que liga cada membro do grupo ao líder, às representações que regulam o funcionamento da coletividade. Nessa composição, forma-se um sistema que o autor propõe pensarmos como constituindo um corpo materno. A metáfora se justifica pois, na formação coletiva, esse sistema assume uma função de amparo e proteção aos seus membros (ao proporcionar simbolizações, sublimações, recalcamentos, continência), comparável à função de objeto para-angústia, e, ao mesmo tempo, é lócus de escoamento, investimento e destinação de elementos sexuais.

Isso nos remete a Bleichmar (1994) e sua conceituação de "duplo comutador": a função materna, ao mesmo tempo em que organiza, estabiliza, integra, também possui uma via de provocação, sexualização. A massa, enquanto corpo materno, pode ser compreendida como fornecedora de elementos integrativos e narcisizantes, de destinos para o escoamento libidinal (satisfação) e de elementos enigmáticos e excitantes que demandarão, por parte dos membros, novas traduções para a vida coletiva.

Se a ligação entre os membros do grupo requer o recalcamento da agressividade (e sua expulsão para fora desse sistema), para Enriquez (1999) esse processo nunca se dá por completo. Segundo o autor, podemos vislumbrar a violência na ligação com o líder, pois o laço de amor que o sustenta enquanto ideal, por ser ambivalente (como toda relação humana), se transforma em ódio, levando-o a ser morto, factualmente ou simbolicamente, em meio a lutas pelo poder e ao surgimento de substitutos. Entre os membros a agressividade subsiste, também, na eleição de inimigos internos, que devem ser liquidados ou expulsos da massa. Podemos pensar nas ideologias de classe que mantêm e naturalizam privilégios de determinados grupos ou classes em relação a outros dentro de uma mesma comunidade de “irmãos”. Como afirma André (2000), a exigência de igualdade perante a lei se impõe mais como formação reativa que como ideal humanístico, impedindo que qualquer dos irmãos avance para a obtenção de privilégios ou distinções ante os demais. Nesse sentido, podemos pensar que uma comunidade se estabelece às custas de elaborações (formações reativas, sublimações) que permitem o acesso ao simbólico.

Na concepção de Freud sobre a dinâmica grupal, predomina uma organização a partir do Complexo de Édipo ou do modelo familiar, a partir da horda primeva, que dá à massa uma característica neurótica, como observa Anzieu (2012). Porém, para este autor, assim como cada indivíduo possui sua organização psíquica, o mesmo ocorre com os grupos. A organização edipiana é própria da estrutura familiar; quando esta fracassa, será nos grupos que os indivíduos buscarão perfazer um projeto edipiano abandonado ou inconcluso. Assim, os grupos podem adotar o Édipo tanto como pseudo-organizador, 
como sistema defensivo que protege seus membros de regressões arcaicas, pré-genitais, mas também podem se organizar e favorecer regressões pré-genitais, isto é, se organizar não a partir de uma instância ideal (ideal do eu), mas de acordo com um eu (ego) defensivo ou a partir do isso (id).

De acordo com Enriquez (1999), a democracia e seu ideal de igualdade entre seus membros não geram uma sociedade pacífica e harmoniosa, mas uma intensa luta e competição interna. O outro, transformado em semelhante, se torna adversário em uma luta incessante na qual se deve negociar, rivalizar, confrontar, em busca de diferenciação. A desigualdade de condições entre ricos e pobres para disputar igualmente no mercado econômico, o domínio de grupos e partidos em disputa pelo poder no âmbito da liberdade política, as restrições encontradas para exercício da liberdade de expressão e criação e a violência exercida pelo Estado desmentem a imagem idealizada que se tem da democracia. Essa violência gerada no interior das sociedades democráticas, segundo o autor, é gerida pelo Estado, que se impõe sobre as vontades individuais e busca impedir a dissolução da comunidade, monopolizando e legislando sobre o uso da força e da violência. De acordo com Guibernau (1997), os Estados modernos surgem a partir do final do século XVIII, organizando as nações em torno de um determinado território, submetidas a governos que controlam, classificam e concentram o monopólio sobre o uso legítimo da força e da violência.

Para Guibernau (1997) o nacionalismo, enquanto fenômeno psicológico de forte carga emocional, que se relaciona ao sentimento de pertença comunal, de unidade coletiva, de um "caráter" nacional, funciona politicamente como ideologia ao supor a perfeita confluência entre Estado e nação, ou seja, entre a estrutura de poder e a comunidade. No caso dos Estados oriundos da colonização (como é nosso caso), a autora afirma que o nacionalismo é utilizado pelas elites que, visando seu pleno estabelecimento nas estruturas de poder, impõem uma "cultura oficial" a fim de unificar as diferentes culturas existentes no território, o que pode levar ao extermínio e subjugação das minorias.

No caso brasileiro, a ideia de que pertencemos a uma nação e que possuímos uma identidade em comum consiste em algo recente em nossa história.
De acordo com Chauí (2014), essa construção teve início após a independência do país em relação à metrópole portuguesa (1822), donde surgiu a necessidade, a partir das elites dirigentes, de se forjar traços e características que nos singularizariam e que supostamente nos fariam diferentes das demais nações, unificando-nos em torno de elementos identificatórios, como o compartilhamento de uma língua comum e de símbolos e tradições inventadas para dar sentido à vida coletiva. A partir de 1830, segundo a autora, o Brasil e o brasileiro passaram a ser objetos de teorizações a respeito de seus supostos caráter e identidade, esforços que sofreram variações ao longo do tempo dependendo do momento sociopolítico, da classe social dos autores e das ideias predominantes na Europa.

Ao recorrermos às obras de alguns "intérpretes do Brasil”, como Oliveira Vianna (1987), Paulo Prado (1997), Caio Prado Junior (2011), Sérgio Buarque de Holanda (2016), Florestan Fernandes (1976), resguardadas as evidentes diferenças teórico-metodológicas entre os autores, é quase unânime a consideração de que a passagem de "colônia" para "nação" se deu sem uma ruptura definitiva com as estruturas precedentes (coloniais), preservando características concomitantemente ao advento dos ideais liberais na constituição do Estado nacional. Uma das principais "heranças" consiste no poder e na dominação pessoal prevalecentes sobre o interesse coletivo. A figura do patriarca/senhor/latifundiário, que amalgama, ao mesmo tempo, a lei e o arbítrio, o amparo e a exploração, impregnou as relações sociais estabelecidas no país, marcando-as pela subalternidade às figuras de autoridade, o que dificultaria o pleno estabelecimento de um pacto social. O patriarca concentrou, em si, o papel de tutela das camadas pobres e sempre atuou na defesa de seus interesses particulares, primeiramente no limite de suas propriedades e, mais tarde, na estrutura do Estado.

Existe uma espécie de consenso no pensamento social brasileiro sobre nossa deficitária solidariedade social. A estrutura colonial disforme, baseada em laços de parentesco, formada por pequenos grupos consanguíneos e de proximidade relacional, será transformada em "nação" a partir da constituição de um Estado nacional de maneira, digamos, prematura ${ }^{3}$.

\footnotetext{
${ }^{3}$ Sobre este aspecto, apenas para ilustrar o que acabamos de expor, Oliveira Vianna (1987) considera tal formação social como rudimentar, com poucos elementos agregadores; Paulo Prado (1997), assim como Sérgio Buarque de Holanda (2016), a define como um corpo amorfo,
} 
Compreendendo a formação da massa psicológica a partir da constituição de dois laços libidinais, um vertical, direcionado ao líder ou a uma representação unificadora, e um laço horizontal, que agrega a comunidade de "iguais" - originando uma formação em cruz (Ramos, 1997) -, podemos pensar que, no caso brasileiro, a herança colonial fixou uma configuração especial à formação de massa: os laços verticais dessa cruz seriam fortemente investidos, enquanto os laços comunitários, o braço horizontal da cruz, seriam frágeis, debilmente estabelecidos. Vejamos.

O caudilho, senhor de engenho, patriarca do período colonial, operou, como teoriza Franco (1997), uma dominação sobre seus dependentes que se exerceu por meio do favor e da lealdade, em uma aparente relação de complementaridade que ocultou uma relação assimétrica, de dominação do mais forte sobre o mais fraco. A autora afirma que as possibilidades de consciência política das classes subjugadas ficam, assim, estagnadas ou impedidas de tomarem forma.

Segundo DaMatta (1997), a sociedade brasileira se caracteriza pela manutenção de uma rígida estrutura hierárquica, de modo que há uma identificação "de baixo para cima", do subalterno em relação ao superior, em laços de consideração, respeito e favor - laços baseados na pessoalidade. Esse elo vertical sufoca a explicitação de conflitos entre as hierarquias, entre dominantes e dominados, na medida em que o laço horizontal é desinvestido, o que obstrui a identificação horizontal entre os iguais e interdita os conflitos que poderiam subverter ou questionar a ordem hierárquica vigente.

Podemos pensar, então, que no caso brasileiro os conflitos, quando manifestos, raramente expressam, de maneira translúcida, suas raízes assentadas em desigualdades de classe, de gênero ou de raça, dentre outras formas de hierarquização e dominação de nossa estrutura social ${ }^{4}$; ocorre uma espécie de personificação do conflito, por meio da evocação do laço vertical estabelecido com caudilhos. Essas desigualdades são, assim, suprimidas por lutas entre lideranças a serem amadas ou combatidas, cada qual sustentada por laços libidinais verticalmente estabelecidos.
Em relação ao laço horizontal, identificado por parte dos autores como demasiado tênue em relação à ligação vertical, podemos supor que há, aí, uma dificuldade na constituição de uma massa psicológica, dado que estãoobstruídas ou dificultadas as vias de identificação entre os “irmãos", entre os iguais, sobretudo por uma ligação sobressalente com o caudilho. Nossa deficitária solidariedade social seria fruto da carência dessas elaborações ou de elementos identificatórios horizontais devido aos percalços de nossa história, baseada no poder exercido pelas oligarquias e elites, na deliberada asfixia de qualquer movimento social que ameace a hierarquia social instituída, no controle sobre a memória nacional e na produção de recursos mito-simbólicos que atuam na negação da existência de conflito social ou de violência interna a essa massa. Isso se manifesta nos mitos da harmonia entre as três raças (Von Martius) e no mito da democracia racial (presente em Gilberto Freyre), que persistem até os dias atuais em nosso imaginário social.

Compreendendo, portanto, os fenômenos de grandes grupos a partir dos fundamentos expostos até aqui, vejamos se alguma luz pode ser lançada sobre a polarização entre convicções que se evidenciou nos últimos anos em nosso país e sua conformação em torno de uma liderança autoritária. Passemos, então, a uma breve rememoração dos recentes acontecimentos de nossa história. Voltemos, então, a junho de 2013: nosso ponto de partida.

\section{0 gigante acordou... "bipolar" e mal-humorado}

“O gigante acordou!", bradavam os manifestantes durante as Jornadas de Junho de 2013. A massa "amorfa" e até então "passiva" parecia se revoltar. Inicialmente organizadas por movimentos sociais que protestavam contra o aumento do preço das tarifas de transporte público, logo se transformaram em uma espécie de catarse coletiva, quando mais de um milhão de brasileiros tomaram as ruas do país expressando uma indignação generalizada e sem pauta definida ou unificada, mas múltipla (Antonino, 2018).

um mero ajuntamento de pessoas; para Caio Prado Junior (2011), uma massa incoerente, desconexa, de laços tênues, rudimentares e primários; Florestan Fernandes (1976) a compreende como estamental e sem condições mínimas para ser considerada uma sociedade.

${ }^{4}$ Devemos mencionar, como exceções, os movimentos indígenas, o Movimento dos Trabalhadores Sem Terra (MST), os movimentos negros, os movimentos feministas e os movimentos LGBTQIA+, por exemplo. 
Para Bolle (2016), o país, sob o governo do Partido dos Trabalhadores (PT) de Dilma Rousseff, atravessava um período de recessão econômica que levou a população a se deparar com desemprego, alta da inflação e sensação de insegurança relacionada ao crescimento da violência urbana. A esse quadro de crise econômica, soma-se também uma crise política e moral, na medida em que casos de desvios de dinheiro público, por meio da Operação Lava Jato, ganharam os holofotes das grandes mídias, o que acarretou o estabelecimento, pela opinião pública, de uma íntima relação entre políticos e corrupção (sobretudo daqueles filiados ao PT), bem como da ideia de que a corrupção seria a raiz dos males do país (Almeida, 2018).

Inicialmente sem pauta unificada, esses movimentos expressavam, segundo Mendes (2018), sobretudo um desejo de democracia: na esteira dos contemporâneos levantes da chamada Primavera Árabe ${ }^{5}$, milhares de cidadãos comuns, sem filiação partidária ou ligados a ativismos organizados, insurgiram em torno de uma busca por renovação ou expurgação das relações promíscuas entre Estado e mercado, de modo que a corrupção era um denominador comum, compartilhado, contra o qual todos desejavam lutar.

Birman (2014) nota que essas manifestações de junho de 2013, por suas características de dispersão, descentralização e transversalidade, se organizaram em torno do estabelecimento de laços horizontais, em detrimento da verticalidade de laços (submissão ou dependência de bandeiras e/ou lideranças). Nesse sentido, o autor defende ter ocorrido não um fenômeno de massas (que pressupõe a ligação vertical a uma liderança), mas de multidão. Pensamos que essa organização em "multidões" ocorreu na fase inicial dos protestos, que se caracterizou, portanto, como um estádio transitório, mas logo adquiriu uma conformação de submissão a lideranças bem definidas, como veremos.

As manifestações híbridas e difusas logo passaram a se organizar em torno de pautas conservadoras ou politicamente identificadas à direita. Com apoio do grande capital e afastamento de sua base social, o governo petista, afirma Ab'Sáber (2015), passa a sofrer um duro golpe a partir da organização massiva do "homem conservador médio", antipetista e anticomunista por natureza devido à sua histórica ligação fantasiosa à proteção arcaica pelo poder patriarcal.
M. M. Ribeiro (2018), analisando os grupos organizados a partir de redes sociais, afirma que, inicialmente, as páginas anticorrupção se tornaram as de maior interação nos ambientes virtuais no período e logo foram seguidas por grupos e núcleos de páginas mais identificadas ao campo conservador, que compartilhavam o ódio ao PT e à esquerda de maneira geral, bem como a defesa de propostas conservadoras em termos morais, liberais e totalitárias, tais como: o encarceramento ou morte sumária de pessoas em situação de conflito com a lei; a defesa de uma educação rígida e livre de ideologias de esquerda, a fim de preservar a inocência das crianças e as tornar disciplinadas; e até mesmo uma intervenção militar para salvar o país de uma suposta dominação comunista, que estaria pervertendo os valores fundamentais da família brasileira e dos cidadãos de bem.

Parte dessa rejeição ao PT, para Mendes (2018), consiste em um efeito provocado pela própria ineficiência do governo em atender aos clamores populares, ao agir por meio da repressão aos movimentos de rua, disseminar o medo generalizado (por meio da mistificação da figura de Lula, com o qual todos teriam uma dívida, e da adjetivação dos discordantes como parte de um polo inimigo ao governo), bem como ao manter um pacto oligárquico nas eleições de 2014 (aliança do partido aos setores mais conservadores do Congresso) e adotar uma agenda econômica fracassada nos primeiros meses do segundo mandato de Dilma Rousseff. Ab'Sáber (2015) observa que o governo havia se distanciado de suas plataformas de sustentação: os movimentos sociais já não se viam representados pelo PT e as elites econômicas (capital local) buscavam outras alternativas que atendessem às suas demandas.

Para Mendes (2018), tais ações promoveram o entrincheiramento das manifestações de junho de 2013, esvaziando sua potência híbrida transformadora ao polarizar pontos de tensão surgidos nos levantes, sobretudo nos apaixonados embates eleitorais de 2014 e 2018. Configurou-se, então, a divisão da sociedade em uma guerra cultural entre dois lados belicosos, pouco dialógicos, em uma clivagem insuperável que se retroalimenta conformando-se em torno de certas representações de "trincheira", cindidas entre o ativismo e a militância de esquerda

\footnotetext{
${ }^{5}$ Denominação atribuída aos levantes populares ocorridos a partir do final de 2010 em países do norte da África e do Oriente Médio, como Egito, Tunísia, Líbia e Síria (Brancoli, 2013).
} 
e o "cidadanismo difuso" (Mendes, 2018, p. 134) que buscou em símbolos nacionais supostas unidade e identidade nacionais ("o verde-amarelismo", sobre o qual trataremos mais adiante), perdendo sua capacidade inovadora ao se identificar a pautas e grupos conservadores.

Uma nova direita se desenhou no país, organizada, segundo Miguel (2018), a partir de um tripé discursivo: o libertarianismo (a defesa das propostas neoliberais), o fundamentalismo religioso (de matrizes pentecostal e neopentecostal) e o discurso anticomunista (grande aversão à esquerda, sobretudo ao partido governista, o PT).

Passados dois intensos e apaixonados processos eleitorais (em 2014 e 2018) e o fim agonizante dos aproximadamente 14 anos do PT no poder terminando com o processo de impeachment da então presidenta Dilma (em 2016) e a prisão de sua principal liderança, Lula, em abril de 2018 -, assistimos a chegada à presidência da República de um presidente de inspiração conservadora e de extrema-direita, Jair Messias Bolsonaro.

De acordo com pesquisa de M. M. Ribeiro e Ortellado (2019), as principais temáticas levantadas por Bolsonaro durante sua campanha e que contaram com a adesão de seus eleitores, consistiram em: antipetismo; discurso antissistema (acusação de que todo o sistema político e midiático é corrupto e contrário aos interesses da nação); defesa do conservadorismo e de supostos valores tradicionais da família (que estariam ameaçados pelo crescimento dos movimentos feminista e LGBT); apelo à meritocracia contra políticas sociais (como programas de transferência de renda para população em situação de pobreza e extrema pobreza e políticas de cotas raciais); retórica anti-intelectualista (guerra cultural contra professores, intelectuais e artistas, que seriam responsáveis pela difusão de ideias progressistas); punitivismo (apoio à maior flexibilização para porte de armas, aumento das penas para indivíduos que cometeram crimes e aversão à Declaração Universal dos Direitos Humanos); e exacerbação de símbolos nacionalistas (sem que isso implique em uma real política nacionalista).

\section{Entre duas fascinações: de Lula a Bolsonaro}

Para compreendermos a ascensão de Bolsonaro ao poder, de alguma forma temos que remeter a seu, digamos, par antitético: Lula; afinal, uma forte rejeição ao petista por parte de uma parcela da população atuou de forma propulsora à candidatura e eleição do capitão ao cargo máximo do país. Trata-se de duas personagens que exercem e exerceram significativo fascínio sobre a massa, polarizando amor e ódio em seu interior.

Para Ab'Sáber (2011), Lula se elegeu, em sua quarta disputa eleitoral pela presidência da República, sustentando um discurso conciliador em que prometia unir esquerda e direita, pobres e ricos, políticas sociais e mercado - promessa cumprida ao longo de seus dois mandatos (2003-2010) -, e entregou a faixa presidencial com índices muito elevados de aprovação popular, superiores a $80 \%$.

Ab'Sáber (2011) afirma que o governo Lula, em sua busca de conciliação entre diferentes setores e classes da sociedade, abandonou o discurso de luta de classes característico de seu partido (PT) e se articulou aos setores mais arcaicos e patrimonialistas da política nacional ${ }^{6}$, conciliando ações voltadas às parcelas mais pobres a um liberalismo econômico que agradava ao "mercado". Dessa forma, desarticulou oposições a seu governo, integrando as parcelas mais pobres ao consumo e oportunizando às parcelas mais ricas o aumento de sua riqueza.

Ab'Sáber (2011) considera que o presidente Lula foi imantado com uma espécie de "carisma pop": além de estabelecer facilmente um laço identificatório com a grande massa mais pobre, sendo um "igual" que simbolicamente os representava no poder, foi agraciado pelas classes mais abastadas, escapando da crítica, mesmo nos momentos mais delicados, quando das denúncias de corrupção que rondavam seu círculo de relações. Mendes (2018) pensa que o governo petista promoveu uma mistificação da imagem de Lula, diante do qual todos os brasileiros adquiriam uma dívida simbólica e os críticos/discordantes eram rotulados como inimigos do país - burgueses, mal-agradecidos, alienados.

\footnotetext{
${ }^{6}$ Nos referimos sobretudo à aliança com o Partido do Movimento Democrático Brasileiro (PMDB), historicamente ligado às lutas democráticas no período da ditadura militar, mas que dividiu-se em uma ala progressista e outra conservadora (o denominado "centrão"). A ala progressista (formada por socialistas democráticos e liberais progressistas) deu origem, em 1988, ao Partido da Social Democracia Brasileira (PSDB), preservando, no PMDB, um bloco de políticos que atuam, desde então, de maneira "fisiológica" no Congresso, como um bloco governista independentemente de o governo ser de direita ou de esquerda (Schwarcz \& Starling, 2015).
} 
Intensamente amado, precedido unicamente por Getúlio Vargas, afirma Ab'Sáber (2011), Lula cai em desgraça a partir da recessão econômica de sua sucessora, Dilma Rousseff, e das constantes denúncias de corrupção envolvendo seu governo, quando passou a ser alvo de intenso ódio. Se investimentos afetivos são, por natureza, ambivalentes, o ódio direcionado à figura de Lula por uma parcela da população só se torna possível porque, outrora, fora intensamente amado.

Dilma representava uma continuidade do "poder mágico" de Lula; porém, devido à recessão econômica à qual já aludimos e ao jogo de interesses do grande capital, para o qual o governo petista já não se mostrava uma boa parceria, sua figura e a de Lula passam a ser execradas. Para Ab'Sáber (2015), o ódio exacerbado direcionado a Lula resulta do encantamento mágico que sua figura carismática exerceu sobre a população, o que desencadeia o ódio como uma tentativa de desfazer o laço idealizado, desligar tal fascinação diante de um amor frustrado pela realidade.

Temos então um quadro propício para a emergência de uma instabilidade no corpo social: recessão, incertezas, desemprego, sensação de insegurança, escândalos de corrupção, desesperança... elementos que nos levam à beira do desamparo. Se nossa coletividade vivenciava há alguns anos um período de estabilidade, confiança e de certa invisibilidade de suas tensões internas, nesse contexto crítico entendemos que há um colapso dessas representações coletivas que nos mantinham protegidos e amparados. Com o fracasso dessas representações, fenômenos regressivos ganham força no interior da massa, enquanto mecanismos de defesa que buscam recompor sentidos para a existência coletiva e traduzir o desamparo. Formou-se, assim, um sistema cindido, polarizado, entrecruzado por defesas primitivas, como a projeção e a negação, levando à busca por representações que novamente respondam a algum senso de pertença grupal. Abaladas as representações que traziam alguma segurança e estabilidade, formou-se um terreno propício para a emergência de discursos polarizados, com visibilidade para grupos de direita e extrema-direita? ${ }^{7}$.

O discurso de Bolsonaro ganha força e adesão nas redes sociais. Prometendo realizar uma limpeza contra as esquerdas, identificadas à "sujeira", trazer a volta dos valores da "família tradicional" e governar o Brasil com punhos de ferro, ao estilo militar, sustentou a imagem de um sujeito honesto, "ficha limpa", incorruptível, contra todo o sistema. Um mito, um herói, um mártir8.

A identificação a sua figura, tal como ocorrera com Lula, certamente foi facilitada ao ser encarado como semelhante, como "um de nós". Seus posicionamentos e postura anti-establishment ("não sou um deles", "contra tudo o que está aí") parecem ter atuado como um forte fator de ligação. O discurso bolsonarista, baseado no medo e nos ataques primitivos aos inimigos, estabeleceu uma identidade de grupo (pessoas de bem), empoderando as massas e trazendo uma forte satisfação narcísica ao tornar cada membro um feroz combatente na luta contra o mal, que se localiza no outro.

Diante da ameaça de queda em desamparo, uma figura onipotente pode ser buscada, segundo Birman (2017), em uma espécie de relação sadomasoquista, na qual a massa, desestabilizada, adere a um líder que, por meio de um discurso que promete a segurança e a retomada de um passado idealizado, mobiliza-os na luta contra algum bode-expiatório, causa de todos os males que afligem a nação - papel atribuído a Lula e seu partido. Diante do desamparo, os indivíduos buscam, na submissão a um protetor absoluto e destrutivo, a segurança e proteção.

O sadismo encarnado pelo líder autoritário, por sua ocupação do lugar de ideal do eu, atua de forma a liberar o sadismo de seus súditos. O líder que promete exterminar seus inimigos libera uma agressividade para o interior da massa, fazendo com que, horizontalmente, se estabeleçam relações de ódio e sadismo para com o diferente, o subjugado, o marginalizado, o "inimigo". Se o lulismo compôs o terreno polarizado, com Bolsonaro o quadro se acirra, incrementando as moções de ódio projetadas no outro.

Pois bem, para depurarmos nossa análise, abordaremos, a seguir, três pilares do discurso bolsonarista que podem nos auxiliar na compreensão de sua escalada ao poder: o apelo a uma intervenção (golpe) militar, o discurso nacionalista e o conservadorismo de fundamentação religiosa.

\footnotetext{
${ }^{7}$ De acordo com M. M. Ribeiro e Ortellado (2019), o crescimento da extrema-direita em alguns países europeus tem sido explicado, pela literatura, pela anomia social - fatores como o desemprego e empobrecimento têm levado à precarização das condições de vida e à desesperança. O fenômeno também é observado por Reich (1988), ao assistir ao crescimento do fascismo pelo mundo no pós-crise de 1929.

${ }^{8}$ Imagem que se solidificou a partir do (ainda) enigmático atentado sofrido na véspera das comemorações da Independência do Brasil, no dia 06 de setembro de 2018, durante passeata em Juiz de Fora, Minas Gerais.
} 


\section{A volta dos militares e os fantasmas do autoritarismo}

Uma das manifestações mais visíveis pós-2013, que consistiu uma tônica da campanha eleitoral de Bolsonaro, foi o forte apelo pela volta dos militares ao poder ${ }^{9}$. O Brasil, que vivenciou uma ditadura militar por 21 anos (1964-1985), nesse momento de crise se vê às voltas com fantasmas de um período sombrio de nossa história.

O estado de exceção brasileiro se trata de um período cuja história se encontra mal narrada, mal resolvida, não devidamente elaborada em nosso corpo social, corroborada pela anistia que igualou torturadores e torturados, deixando os primeiros impunes. Kehl (2016) nos fala da falta de um ato simbólico que demarcasse a inadmissibilidade do uso da violência pelo Estado; Ocariz (2016) afirma que houve uma recusa ou esquecimento da violência dos anos de chumbo, o que ocasionou uma insuficiência de elementos para elaboração do passado e gerou a repetição como sintoma; Ferraz (2016) compreende ter havido apenas uma ab-reação, e não uma reparação, devido à maneira pela qual terminou o regime militar (sem julgamentos); Silva Junior (2016) compreende o silenciamento em torno da ditadura como um "desmentido social" que provoca efeitos traumáticos devido ao não reconhecimento ou à recusa dos crimes cometidos no período. Esses autores são unânimes ao conceber que a anistia deu autorização simbólica para que o Estado continuasse perpetrando sua violência institucionalizada contra seus cidadãos, enquanto "enclaves da exceção no interior do estado democrático de direito" (Ferraz, 2016, p. 114).

Carregando, portanto, um significativo lapso em nossa memória coletiva, contaminada e impregnada pela versão oficial da história ${ }^{10}$, os apelos pela volta dos militares ao poder por uma parcela da população surgem, no contexto de crise, enquanto uma tentativa mágica de regressão a tempo semiedênico, quando reinavam a ordem e o progresso imaginários.

Trata-se de uma saída defensiva que busca em uma liderança despótica a solução para calar a divergência, eliminar o "outro-diferente", silenciar questionamentos; uma forma regredida de destruir e aniquilar o conflito. A saída autoritária, para Enriquez (1999), se fundamenta sobre a impossibilidade de comunicação entre os indivíduos e a incompatibilidade radical entre seus posicionamentos: o diferente ameaça a estabilidade do eu e traz o medo da perda da razão, fazendo com que os indivíduos neguem a existência deste outro-diferente e busquem o julgamento do autocrata.

A volta da ditadura oferece, em um momento de crise social, uma ilusão de segurança e estabilidade, por meio da sustentação e identificação a um pai forte e protetor de seus filhos, enquanto exerce sua violência contra um recorte específico da população. Um líder tirano e absoluto oferece, também, contenção aos próprios desejos incontroláveis de corromper o corpo materno da formação social daqueles que o demandam, ao mesmo tempo em que combate os inimigos internos que, alvo de projeções, se tornam objetos persecutórios.

O inimigo interno passa a representar uma espécie de corpo estranho penetrado no corpo materno; corpo estranho que desestabiliza esse sistema em um momento caótico e mobiliza defesas para expulsão. Bohleber (2008) pensa que o inimigo representa o irmão rival que vem destruir a fusão narcísica e idealizada com a mãe coletiva - portanto, em um grupo bastante regredido; na busca por recuperar um corpo materno homogêneo, puro, intenta-se eliminar as ambivalências em seu interior por meio da intolerância ao diferente (considerado impuro, sujo, corrupto).

Assim, no que Ab'Sáber (2015) chama de "comunismo tardio", o ódio se volta contra o "esquerdista", que deve ser expulso para Cuba ou para a Venezuela, pois são corruptores da pátria-mãe. Observa o autor que são longínquas as raízes do horror ao comunista, presente nas duas ditaduras brasileiras do século $\mathrm{XX}^{11}$ e atualizado neste momento de crise. O "lado vermelho" dessa polarização constitui receptáculo de vários elementos repulsivos para o lado "verde e amarelo", como a corrupção, a imoralidade, a sujeira, a pedofilia e toda ordem de perversões, que servem de justificativa para a instauração de regimes totalitários.

\footnotetext{
${ }^{9} \mathrm{O}$ apelo se concretizou não apenas no pleito para a presidência da República (ele próprio, Bolsonaro, um militar), mas também pelo grande número de candidatos ligados à segurança pública eleitos para cargos de deputado e senador em todo o Brasil nas últimas eleições.

${ }^{10}$ A versão de que o golpe militar se trata de uma "revolução" para salvar o país dos comunistas "comedores de criancinhas", reproduzida até os dias atuais, se trata de uma das formas com as quais os ditadores operaram um controle da memória e da narrativa, que era lecionada nos bancos escolares durante os anos de chumbo e, inclusive, segundo Saint-Clair (2018), fez parte da formação escolar na juventude de Bolsonaro.

${ }^{11} \mathrm{O}$ autor se refere ao Estado Novo, período ditatorial de Getúlio Vargas de 1937 a 1946, e à já referida ditadura militar, de 1964 a 1985.
} 
O medo do comunista pode também nos remeter ao medo da horizontalidade das relações, já que, de acordo com DaMatta (1997), nossa sociedade está assentada em uma rígida hierarquização, na qual os laços verticais (com o patrão, com o líder, com o aristocrata, com o senhor) sobressaem à ligação entre os iguais. Comunizar, igualar, apresenta o risco da perda de pequenos e grandes privilégios, o medo de empobrecer, a repulsa a se igualar ao outro subalterno, inferior. De acordo com Silva Junior (2016), a horizontalidade nas relações pressupõe que relações de poder, que instituem hierarquias e o uso da violência, sejam abandonadas em nome de relações de solidariedade, nas quais todos se reconhecem, pela mutualidade, vulneráveis. No caso brasileiro, nos parece que a rígida hierarquia é camuflada por elementos mito-simbólicos e ideológicos que se encontram impregnados em nossas instituições e relações, heranças de nosso sistema baseado na submissão ao patriarca, na produção de representações como o mito da democracia racial (que pressupõe a miscigenação harmônica), na representação de um país pacífico de povo amistoso, na crença na meritocracia, no racismo não reconhecido, no machismo que atravessa nosso corpo social e nos símbolos patrióticos que buscam uma homogeneização e assunção de uma identidade brasileira imperiosa, compulsória.

\section{"Brasil acima de tudo": o ataque do verde-amarelismo}

O patriotismo foi um dos alicerces das manifestações ocorridas a partir de junho de 2013. O "gigante" acordara: os cidadãos cantavam o hino nacional, vestiam-se com as cores da bandeira do Brasil e impediam o hasteamento de qualquer bandeira partidária nas manifestações - algo que, para Mendes (2018), seguia uma lógica não-representativa, de rejeição à submissão a entidades pré-existentes e autoridades instituídas, e não configurava um sinal de uma massa fascista ou alienada. Para Birman (2014), isso demonstrava uma descentralização dos grupos (não submetidos a uma representação política) e uma dispersão das palavras de ordem. Como vimos, gradativamente esse movimento catártico inicial se transformou em um movimento de direita e conservador, de caráter anti-petista, sustentando um nacionalismo exacerbado que rejeita as diferenças.

Para Chauí (2014), o patriotismo surge no contexto dos conflitos internos entre operários e burgueses, enquanto uma "religião cívica", no momento em que ameaças ao sistema capitalista se tornam mais factíveis. O nacionalismo de Estado, gestado pelos intelectuais burgueses, oferece elementos simbólicos para a manutenção e/ou fortalecimento da comunidade e identifica uma verdadeira "alma" do povo, sua raça, suas tradições.

O verde-amarelismo, segundo Chauí (2014), se evidenciou sobretudo nas políticas do Estado Novo, a ditadura de Getúlio Vargas (1937-1946). Durante esse governo, marcado por centralização do poder, anticomunismo e exacerbação do nacionalismo (com a queima das bandeiras dos estados, obrigatoriedade de execução do hino nacional nas escolas e exigência de os sambas-enredos das escolas de samba abordarem temas nacionais, por exemplo), o verde-amarelismo atuou na neutralização da luta de classes por meio do prevalecimento da cooperação de todos pela nação.

É preciso recordar que a identidade brasileira, conforme expõe Chauí (2014), antes de se caracterizar como uma entidade a-histórica, se trata de uma construção forjada em meados do século XIX, a partir da necessidade das elites dirigentes em estabelecer elementos comuns (língua, tradição, símbolos, história) que fornecessem vias de identificação aos membros de uma coletividade. Assim, o que nos identifica como brasileiros parte de uma construção histórica comprometida com a manutenção do poder nas mãos das elites dirigentes e a eliminação de tensões e conflitos em nome de uma suposta natureza agregadora, mas extremamente excludente.

Estados totalitários, segundo Enriquez (1999), tendem a resgatar os mitos fundadores da nação, ou seja, se apoiam em narrativas atemporais e inquestionáveis que trazem um sentido, ordem, uma nova esperança à vida em comum, orbitando em torno de uma missão, uma predestinação, uma natureza originária da qual não se deve desviar. A retomada dos mitos surge enquanto medida para recolocar a nação nos trilhos certos, já que seu atual estado de caos e desamparo é atribuído, pelos líderes totalitários, como responsabilidade de governos anteriores. Essa ilusão compartilhada pela massa apazigua os indivíduos quando vivenciam um sentimento onipotente de si (enquanto participante da coletividade) e da comunidade.

Algo semelhante parece portar o lema "Brasil acima de tudo”. Em seu bojo, evidencia-se o recurso 
à violência do Estado para a eliminação de tudo o que é entendido como obstáculo à homogeneização dessa massa: seus inimigos, entendidos como corruptores dos valores tradicionais da nação e obstáculos a seu desenvolvimento.

Os símbolos nacionais são evocados para manter a ordem que, aliás, estampa nossa bandeira: uma insígnia que mobiliza uma defesa ante o medo da dissolução da massa, da perda de sentido comunal e dos fantasmas de corruptores que estariam infiltrados no corpo social pervertendo-o, colocando os valores de "cabeça para baixo", tirando a inocência das crianças nas escolas, alastrando práticas imorais e atentando contra aquilo que funda a vida comunitária, sobre os diques da sexualidade polimórfico-perversa.

Podemos entendê-lo enquanto um movimento defensivo no interior da massa, enquanto recurso para se estabelecer uma massa unida e coesa diante da ameaça de sua dispersão, dissolução, sobretudo em tempos de crise e desamparo. Para o estabelecimento dessa unidade, as forças do Estado são requeridas para impor uma ordem, uma disciplina, uma moralidade cívica. O verde-amarelismo reatualizado sai às ruas para a restauração dos valores supostamente perdidos ou desviados pelos comunistas e pelos movimentos negro, feminista e LGBTQIA+, defendendo a destruição dos não-patriotas e perversores dos valores fundamentais da família brasileira.

\section{"Deus acima de todos": o Brasil nos planos de Deus}

A religiosidade é um importante elemento constitutivo da formação social brasileira. Se, por um lado, se oferece enquanto amparo e fornecedora de sentido aos sujeitos, contribuindo com vários aspectos de nossa cultura - em nossas artes, festas populares, nos códigos mito-simbólicos que organizam a via coletiva -, por outro, como nos diz Freud (1921/1996), por se tratar de uma religião de amor voltado apenas para os "irmãos" que dela comungam, o cristianismo, desde os princípios da colonização, atuou enquanto instrumento de domínio, exploração e extermínio das populações indígenas (D. Ribeiro, 2015) e de perseguição e tentativas de destruição das culturas dos povos africanos (Nascimento, 1978). Apesar de ter sofrido transformações ao longo dos séculos, de alguma forma essa característica persiste até os dias atuais, por meio de atos de intolerância e de rejeição à diversidade e ao diferente, o que se torna mais visível no seio de algumas manifestações religiosas contemporâneas.

Como afirma Almeida (2019), Bolsonaro, ao longo de sua campanha, apresentou-se como um candidato cristão que, apesar de católico, mostrou-se simpático às religiões de matriz protestante, sejam elas históricas, pentecostais ou neopentecostais. Atraídos por uma pauta de costumes (em defesa da família, dos "homens de bem", contra a corrupção), os eleitores evangélicos fizeram a diferença e desequilibraram o resultado das eleições de 2018.

Partidos e políticos evangélicos estiveram na base de apoio aos governos petistas, destaca Almeida (2019), quadro que se transformou paulatinamente nos últimos anos, quando discursos conservadores ganharam força enquanto reações aos medos que assombravam nosso corpo social, como o desemprego e a violência urbana. Segundo o autor, segmentos evangélicos se somaram a outras forças sociais, ajudando na composição da onda conservadora que seguiu os levantes de 2013.

Nessa conformação, há que se destacar o papel dos evangélicos neopentecostais, segmento que, segundo Mariano (1999), introduziu no movimento evangélico uma série de novas interpretações das mensagens bíblicas, instaurando uma nova forma de relação fiel-deus. Uma delas consiste na Teologia da Prosperidade, segundo a qual a busca individual pela riqueza é sinal de bênção divina; logo, a riqueza deve ser buscada com fé e atitude empreendedora pelo fiel, o que o distancia de uma postura resignada diante da pobreza e da exclusão - sinais de fracasso do indivíduo. Conforme Almeida (2019), o ideal não corresponde à igualdade, mas sim à ascensão do indivíduo sobre a massa.

Outra inovação consiste na Teologia do Domínio que, segundo Mariano (1999), caracteriza-se como um sistema de crenças de que os males que assolam a vida dos homens se devem à falta de fé e à não observância das leis de Deus, que abrem espaço para o trabalho demoníaco. Dores de cabeça, conflitos familiares, desemprego, subdesenvolvimento, pobreza, corrupção, fome, entre outras mazelas individuais e sociais passam a ser interpretadas como efeitos da falta de fé e da ação do Diabo na realidade nacional. O mundo passa, então, a ser compreendido a partir de uma guerra universal entre Deus e seu exército de fiéis e o Diabo e seus demônios. Nessa trincheira, o fiel é convocado a participar ativamente da "caça ao demônio" 
e, no plano da política, isso se traduz no voto em candidatos comprometidos com evangelizar o mundo e transformá-lo para a honra e glória de seu deus.

Há, portanto, um nítido projeto de poder com uma face econômica (adesão ao ideário liberal) e outra moral (domínio sobre o inimigo), implementado por meio de um grande investimento por parte dessas denominações em eleger membros de suas congregações para cargos políticos em todos os níveis, a fim de conquistar postos importantes no âmbito político para a defesa de seus interesses e de sua visão de mundo.

É sobre essa base teológica que se assentou um dos lemas da campanha bolsonarista: "Deus acima de todos". Ao se anunciar enquanto um candidato cristão, amparado, sobretudo, por algumas ramificações do segmento evangélico, Bolsonaro se coloca em uma missão quase messiânica de alinhar a massa aos planos e desígnios divinos, valendo-se da pré-existência de uma ligação forte entre essa massa e a religiosidade. No contexto da crise social nos idos de 2013, a resposta religiosa se apresenta sedutora às massas, necessitadas que são de ilusões, no sentido freudiano, para sua sustentação. Propôs, então, uma ligação entre a massa e a divindade, interposta por um líder-instrumento de uma força superior.

No contexto de uma massa cindida entre dois polos de antagonismos políticos e sociais (de classes), a moralidade e a visão de mundo evangélica que compreende o mundo em uma luta eterna do "bem" contra o "mal" - somam-se e agregam novos elementos ao conflito: "homens de bem" e "defensores da família" passam a digladiar contra "pervertidos" e "defensores de bandidos". Este outro, tornado estranho e, portanto, inimigo ("o inferno são os outros", nos disse Sartre), passa a ser repositório de projeções e fantasias que remetem a uma possível perda de controle egoico e acabando envolvidas em uma aura demoníaca, que precisa ser exorcizada, excomungada, dominada.

\section{Para concluir: uma massa paranoide}

Para encerrar, podemos então pensar que a escolha de uma liderança com posicionamentos identificados à extrema-direita, como analisamos anteriormente, consiste no ponto culminante de um complexo fenômeno de massas que se desenrolou ao longo dos últimos anos. Este corpo social, que vinha sendo governado, até então, por meio de um processo de pacificação das tensões sociais (que pode ser lido como uma espécie de recalcamento do conflito), sofre um colapso a partir da crise econômica e política. Os conflitos, antes represados, vieram à tona, levaram à ruína das representações que mantinham o corpo social minimamente agregado e demandaram que os sujeitos se abrigassem em novas representações que oferecessem sentidos para a vida comunitária.

Kernberg (2000) afirma que, em momentos de crise e instabilidade, as formações coletivas podem sofrer regressões - seja psicopática, depressiva ou paranoide. Um processo eleitoral ocorrido em um momento de crise social, segundo o autor, potencializa a tendência a uma regressão paranoide, liberando uma agressividade no interior da massa que fomenta conflitos grupais, que se tornam inimigos entre si.

Condições sociais, econômicas, culturais ou históricas instáveis, turbulentas e potencialmente ameaçadoras ativam um nível mais profundo de regressão paranóide: a eleição por vir é percebida como uma ameaça em potencial e também como uma oportunidade de desafiar e superar o inimigo imaginário. Os subgrupos sociais tornam-se fortemente divididos e servem como alvos para a projeção da agressão e das distorções paranóides. O potencial para a hostilidade latente na ideologia local e na tradição cultural no que diz respeito à política, à religião, à raça ou à nacionalidade é ativado ao máximo sob tais circunstâncias (Kernberg, 2000, p. 282).

Assolado pela falência das representações que antes davam suporte de sentido e de existência a seus membros, esse corpo passa a tomar uma forma peculiar, não a partir de uma organização neurótica (como a massa teorizada por Freud), mas seguindo um curso mais regressivo, atravessado por defesas primitivas que dão à massa uma configuração paranoide. Internamente, esse corpo se encontra cindido em objetos bons e objetos maus, em mútuo ataque, enquanto defesa contra um desamparo que espreita os sujeitos e os coloca muito próximos de um possível caos. É nesse contexto que o discurso de Bolsonaro cresce, ganha aderência e se torna vitorioso, ao fornecer a uma parte desse corpo social um novo projeto, baseado na luta contra os "objetos maus".

Em momentos de crise, instabilidade e conturbações sociais, os sujeitos, diante do risco de dissolução 
(social e individual), buscam, no discurso paranoico, defesa ante o desamparo, levando as formações coletivas a sofrerem regressões paranoides. Isso porque, afirma Enriquez (1999), o discurso paranoico seduz ao apresentar soluções irracionais tomando, para sua composição, alguns elementos da realidade que se encontram enigmáticos para os sujeitos. Segundo esse autor, o contexto paranoide se torna propício para que se erija um Estado autoritário, baseado na necessidade de defesa diante do perigo, do inimigo, e para que surjam lideranças messiânicas que, iluminadas pela vontade divina, visam purificar e recriar uma nação tornar ilibado o corpo materno.

Portanto, como uma das possíveis respostas aos fantasmas coletivos que voltaram a assombrar os brasileiros, em uma crise que culminou nos levantes de junho de 2013 e se desdobrou até as eleições presidenciais de 2018, corporificou-se um "mito" - um herói revestido de poderes para transformar a realidade nacional, contra tudo e contra todos, ou para recuperar valores perdidos ou deturpados durante os governos de centro-esquerda, responsabilizados pelo caos que então afligia o país. Ocupando esse lugar no imaginário de parcela considerável da população, canalizou um forte investimento afetivo com a promessa de salvar a nação de inimigos corruptores, em um projeto que envolvia, além do cumprimento de uma agenda econômica neoliberal, principalmente uma agenda de valores e costumes que se oferecia como um possível recurso ante as incertezas e angústias de um contexto de crise e polarização.

\section{Referências}

Ab'Sáber, T. (2011). Lulismo, carisma pop e cultura anticrítica. Hedra.

Ab'Sáber, T. (2015). Dilma Rousseffe o ódio político. Hedra.

Almeida, A. C. (31 out. 2018). O motivo que levou à vitória de Bolsonaro, segundo Alberto Carlos Almeida. Poder360. https://bit.ly/2FBXVHF

Almeida, R. (2019). Deus acima de todos. In S. Abranches (Ed.), Democracia em risco? 22 ensaios sobre o Brasil hoje. Companhia das Letras.

André, J. (2000). O privilégio. As duas teorias freudianas do originário social. Psicologia em Estudo, 5(1), 1-34.

Antonino, R. M. (2018). Impeachment e misoginia nas redes sociais: decodificando o conservadorismo pós 2013. Lumen Juris.

Anzieu, D. (2012). O grupo e o inconsciente: o imaginário grupal. Casa do Psicólogo.

Birman, J. (2014). O sujeito da diferença e a multidão. Ide, 36(57), 25-40.

Birman, J. (2017). Arquivos do mal-estar e da resistência. Civilização Brasileira.

Bleichmar, S. (1994). A fundação do inconsciente. Artes Médicas.

Bohleber, W. (2008). Fantasmas coletivos, destrutividade e terrorismo. In S. Varvin \& V. D. Volkan (Orgs.), Violência ou diálogo? Reflexões psicanalíticas sobre terror e terrorismo (pp. 103-121). Perspectiva.

Brancoli, F. (2013). Primavera árabe: praças, ruas e revoltas. Desatino.

Chauí, M. (2014). Manifestações ideológicas do autoritarismo brasileiro. Autêntica; Fundação Perseu Abramo.

DaMatta, R. (1997). Carnavais, malandros e heróis: para uma sociologia do dilema brasileiro. Rocco.

Bolle, M. B. de. (2016). Como matar a borboleta azul: uma crônica da era Dilma. Intrínseca.

Enriquez, E. (1999). Da horda ao Estado. Jorge Zahar.

Fernandes, F. (1976). A revolução burguesa no Brasil: ensaio de interpretação sociológica. Zahar.

Ferraz, F. C. (2016). Estado de exceção e desamparo. In M. A. A. C. Arantes \& F. C. Ferraz (Orgs.), Ditadura civil-militar no Brasil: o que a psicanálise tem a dizer (pp. 107-114). Escuta; Sedes Sapientiae.

Franco, M. S. C. (1997). Homens livres na ordem escravocrata. Unesp.

Freud, S. (1996). Psicologia de grupo e análise do ego. In J. Strachey (Ed.), Edição Standard Brasileira das Obras Psicológicas Completas de Sigmund Freud (Vol. 18). Imago. (Originalmente publicado em 1921). 
Guibernau, M. (1997). Nacionalismos: o estado nacional e o nacionalismo no século XX. Jorge Zahar.

Holanda, S. B. de. (2016). Raízes do Brasil. Companhia das Letras.

Kehl, M. R. (2016). Gozo em estado de exceção: corpos torturados e pessoas desaparecidas. In M. A. A. C. Arantes \& F. C. Ferraz (Orgs.), Ditadura civil-militar no Brasil: o que a psicanálise tem a dizer (pp. 43-58). Escuta; Sedes Sapientiae.

Kernberg, O. F. (2000). Ideologia, conflito e liderança em grupos e organizações. Artes Médicas Sul.

Laplanche, J. (1992). Novos fundamentos para a psicanálise. Martins Fontes.

Laplanche, J. (2015). Três acepções da palavra "inconsciente” no âmbito da teoria da sedução generalizada. In J. Laplanche, Sexual: a sexualidade ampliada no sentido freudiano 2000-2006 (pp. 190-206). Dubliense.

Mariano, R. (1999). Neopentecostais: sociologia do novo pentecostalismo no Brasil. Edições Loyola.

Mello Neto, G. A. R. (1997). Coerção e angústia em psicologia de massas e análise do eu, de S. Freud. Psicologia em Estudo, 2(2), 47-73.

Mendes, A. (2018). Vertigens de junho: os levantes de 2013 e a insistência de uma nova percepção. Autografia.

Miguel, L. F. (2018). A reemergência da direita brasileira. In E. Solano (Org.), O ódio como política: a reinvenção da direita no Brasil (pp. 17-26). Boitempo.

Nascimento, A. (1978). O genocídio do negro brasileiro. Paz e Terra.

Ocariz, M. C. (2016). Clínica do testemunho Instituto Sedes Sapientiae. In M. A. A. C. Arantes \& F. C. Ferraz (Orgs.), Ditadura civil-militar no Brasil: o que a psicanálise tem a dizer (pp. 65-77). Escuta; Sedes Sapientiae.

Prado, P. (1997). Retrato do Brasil: ensaio sobre a tristeza brasileira. Companhia das Letras.

Prado Junior, C. (2011). Formação do Brasil contemporâneo. Companhia das Letras.

Ramos, G. A. (1997). Le social dans la construction freudienne de la psychanalyse. L'harmattan.

Reich, W. (1988). Psicologia de massas do fascismo. Martins Fontes.

Ribeiro, D. (2015). O povo brasileiro: a formação e o sentido do Brasil. Global.

Ribeiro, M. M. (2018). Antipetismo e conservadorismo no Facebook. In E. S. Gallego (Org.), O ódio como política: a reinvenção da direita no Brasil (pp. 85-90). Boitempo.

Ribeiro, M. M., \& Ortellado, P. (Coord.). (2019). Pesquisa com eleitores e não eleitores de Jair Bolsonaro - São Paulo, março-abril de 2019. Monitor das ruas: Grupo de Pesquisa em Políticas Públicas para o Acesso à Informação.

Saint-Clair, C. (2018). Bolsonaro: o homem que peitou o exército e desafiou a democracia. Máquina de Livros.

Schwarcz, L. M., \& Starling, H. M. (2015). Brasil: uma biografia. Companhia das Letras.

Silva Junior, M. R. (2016). Clínica do Testemunho: reconhecimento como caminho de cura. In M. A. A. C. Arantes \& F. C. Ferraz (Orgs.), Ditadura civil-militar no Brasil: o que a psicanálise tem a dizer (pp. 79-89). Escuta; Sedes Sapientiae.

Vianna, O. (1987). Populações meridionais do Brasil: história, organização, psicologia. Itatiaia; Editora da Universidade Federal Fluminense.

\section{Mauricio Cardoso da Silva Junior}

Psicólogo, Mestre e Doutor em Psicologia pelo Programa de Pós-Graduação em Psicologia da Universidade Estadual de Maringá (UEM), Maringá - PR. Brasil.

E-mail: mauricio_cs@hotmail.com

(1) https://orcid.org/0000-0001-6517-4552

\section{Gustavo Adolfo Ramos Mello Neto}

Psicólogo pela Universidade Estadual Paulista “Júlio de Mesquita Filho” (Unesp). Mestre em Psicologia pela Pontifícia Universidade Católica de São Paulo (PUC-SP). Doutor em Psicologia Escolar e do Desenvolvimento Humano pela 
Universidade de São Paulo (USP), com pós-doutorado em Psicanálise pela Université de Paris VII. Professor do Programa de Pós-Graduação em Psicologia da Universidade Estadual de Maringá (UEM), Maringá - PR. Brasil.

E-mail: garmneto@gmail.com

(1) https://orcid.org/0000-0001-6210-8218

Endereço para envio de correspondência:

Universidade Estadual de Maringá. Secretaria do Programa de Pós-Graduação em Psicologia. Av. Colombo, 5790. Campus Universitário. Bloco 10. Sala 08. CEP: 87.020-900. Maringá - PR. Brasil.

Recebido 09/11/2019

Aceito 29/01/2021

Received 11/09/2019

Approved 01/29/2021

Recibido 09/11/2019

Aceptado 29/01/2021

Como citar: Silva Junior, M. C. da, \& Mello Neto, G. A. R. (2022). Do caos ao mito: A ascensão de um presidente pela óptica psicanalítica. Psicologia: Ciência e Profissão, 42, 1-15. https://doi.org/10.1590/1982-3703003230891

How to cite: Silva Junior, M. C. da, \& Mello Neto, G. A. R. (2022). From chaos to myth: The rise of a president under a pshycoanalytic optic. Psicologia: Ciência e Profissão, 42, 1-15. https://doi.org/10.1590/1982-3703003230891

Cómo citar: Silva Junior, M. C. da, \& Mello Neto, G. A. R. (2022). Del caos al mito: El ascenso de un presidente desde el punto de vista psicoanalítico. Psicologia: Ciência e Profissão, 42, 1-15. https://doi.org/10.1590/1982-3703003230891 